\section{POS1327 DO JIA PATIENTS RESPONSE TO RE-TREATMENT AFTER A FLARE DURING TAPERING OF BDMARDS? A DESCRIPTIVE STUDY}

A. García Fernández ${ }^{1}$, A. Briones-Figueroa ${ }^{1}$, L. Calvo Sanz ${ }^{1}$, Á. AndreuSuárez ${ }^{1}$, A. Boteanu ${ }^{1} .{ }^{1}$ Hospital Universitario Ramón y Cajal, Rheumatology, Madrid, Spain

Background: Tapering and withdrawal of biological DMARDs (bDMARDs) is often attempted in Juvenile Idiopathic Arthritis (JIA) patients but data about response to re-treatment after an unsuccessful tapering are scarce.

Objectives: Our aim is to assess response to re-treatment after a disease flare during tapering or withdrawal of bDMARDs and to describe re-treatment strategies.

Methods: A retrospective, descriptive study was conducted in a cohort of JIA patients followed up in a referral hospital and who had received bDMARDs between 2000 and 2019. All JIA patients with at least one flare during tapering or withdrawal were included. Response to re-treatment was defined as achieving Wallace criteria for remission for 6 months.

Results: A total of 142 flares during tapering or withdrawal were identified and included. In 3/142 (2.1\%) patients bDMARDS were not re-started after a flare, 1 due to patient refusal, 2 due to unplanned pregnancy. Main characteristics according to tapering strategies are reported in Table 1.

Table 1. Main characteristics according to tapering strategies. Apso, Psoriatic Arthritis; ERA, Enthesitis related Arthritis; OligE, Oligoarticular Extended; OligP, oligoarticular persistent; Poly RF+, polyarticular rheumatoid factor positive; PolyRF-, polyarticular rheumatoid factor negative; SIIA, Systemic JIA; Und, Undifferenciated.

\begin{tabular}{|c|c|c|}
\hline & Tapering & Withdrawal \\
\hline Cases, n (\%) & $80(57.5)$ & $59(42.4)$ \\
\hline Female, $n(\%)$ & $57(71.3)$ & $36(61)$ \\
\hline Age at diagnosis,years, median (IQR) & $5(2-11)$ & $4(2-11)$ \\
\hline $\begin{array}{l}\text { Age at start of tapering or withdrawal, years, median } \\
\text { (IQR) }\end{array}$ & $17(11-25)$ & $16(8-29)$ \\
\hline \multicolumn{3}{|l|}{ Categories, n (\%) } \\
\hline OligP & $19(23.8)$ & $12(20.3)$ \\
\hline OligE & $15(18.8)$ & $13(22)$ \\
\hline SJIA & $10(12.5)$ & $11(18.6)$ \\
\hline ERA & $12(15)$ & $8(13.6)$ \\
\hline Apso & $7(8.8)$ & $6(10.2)$ \\
\hline Poly RF+ & $9(11.3)$ & $4(6.8)$ \\
\hline Poly RF- & $7(8.8)$ & $3(5.1)$ \\
\hline Und & $1(1.3)$ & $2(3.4)$ \\
\hline Uveitis, n (\%) & $24(30)$ & $16(27.1)$ \\
\hline \multicolumn{3}{|l|}{ Laboratory values, $n$ (\%) } \\
\hline - RF & $15(18.8)$ & $5(8.5)$ \\
\hline - ANA & $45(56.3)$ & $33(55.9)$ \\
\hline \multicolumn{2}{|l|}{ bDMARD target, $\mathrm{n}(\%)$} & $20(33.9)$ \\
\hline - TNF inhibitors & $63(78.8)$ & 45 (76.3) \\
\hline - IL6-blockers & $14(17.5)$ & $5(8.5)$ \\
\hline - IL1-blockers & $2(2.5)$ & 7 (11.9) \\
\hline - Rituximab & $1(1.3)$ & $2(3.4)$ \\
\hline \multicolumn{3}{|l|}{ Line of bDMARD, $n(\%)$} \\
\hline - First & $50(62.5)$ & 45 (76.3) \\
\hline - Second & $18(22.5)$ & $10(16.9)$ \\
\hline - Third & $5(6.3)$ & $2(3.4)$ \\
\hline - Forth & $6(7.5)$ & $2(3.4)$ \\
\hline - Fifth & $1(1.3)$ & $0(0)$ \\
\hline Time in bDMARD treatment, months median (IQR) & $28.4(13.3-52.5)$ & $28.2(13.9-44.6)$ \\
\hline $\begin{array}{l}\text { Remission prior tapering or withdrawal,months } \\
\text { median (IQR) }\end{array}$ & $8(6-12)$ & $8(6-12)$ \\
\hline
\end{tabular}

Fifty-nine out of $80(73.8 \%)$ tapering cases were on remission at 6 months $(6 \mathrm{~m})$ and $42 / 80(52.5 \%)$ at 12 months $(12 \mathrm{~m})$. Regarding dosage schedule adjustments, interval widening was the most frequent in $70 / 80(87.5 \%)$ followed by combined strategy in $7 / 80(8.8 \%)$ and lower dosage in $3 / 80(3.8 \%)$. Median remaining dosage administrated was $54.9 \%$ IQR(50-75). Median time to flare was 14.9 months IQR (5.6-24.7). Median time to re-start of bDMARDs was 0 months min-max(0-13).

After withdrawal of bDMARDs $23 / 59(39 \%)$ cases at $6 \mathrm{~m}$ and $14 / 59$ (23.7\%) cases at $12 \mathrm{~m}$ were on remission. Median time to flare was 4.7 months IQR (2.8-11.4). Median time to re-start of bDMARDs was 1 month min-max (1-6).

Most frequent re-treatment strategies were re-start of standard dosage [tapering $42 / 80(52.5 \%)$, withdrawal $34 / 59(57.6 \%)]$, re-start of previous effective dosage [tapering $28 / 80(35 \%)$, withdrawal $11 / 59(18.6 \%)$ ], change of bDMARD [tapering $6 / 80(7.5 \%)$, withdrawal $6 / 59$ (10.2), re-start of bDMARD and cDMARD [tapering $4 / 80(5 \%)$, withdrawal $6 / 59(10.2)$ ] and re-start of cDMARD [tapering 0/80 (0), withdrawal $1 / 59(1.7 \%)]$.

Overall response to re-treatment was 75/80 (93.8\%) and 53/58 (91.4\%) among tapering and withdrawal, respectively. In 12/139 (8.6\%) patients bDMARD was changed, achieving remission in 11/12 (91.7\%) cases. No factors were associated with response to re-treatment and there were no differences between re-treatment strategies and re-achieving remission $(\mathrm{p}=0.596)$.

Conclusion: Response to re-treatment was high $(92.7 \%)$, no risk factors were identified. Most frequent retreatment strategy was re-start of standard bDMARD dosage in $76 / 139(54.7 \%)$ followed up by restart of previous effective bDMARD dosage in $39 / 139(28.1 \%)$.

Disclosure of Interests: None declared

DOI: 10.1136/annrheumdis-2021-eular.3525

\section{POS1328 HAVE THE CHILDREN WITH JUVENILE IDIOPATHIC ARTHRITIS AN EXCESS OF ADIPOSITY?}

G. Diaz-Cordobes ${ }^{1}$, S. Aguado Henche ${ }^{2}$, L. Martín Pedraz ${ }^{3}$, R. Galindo Zavala ${ }^{3}$ N. Mena-Vázquez ${ }^{4}$, E. Núñez Cuadros ${ }^{3} .{ }^{1}$ Instituto de Investigación Biomédica de Málaga (IBIMA). Hospital Regional Universitario de Malaga. Universidad de Malaga, Reumatología, Málaga, Spain; ${ }^{2}$ Universidad de Alcalá. Facultad de Medicina, Departamento de Anatomía y Embriología Humana, Madrid, Spain; ${ }^{3}$ Hospital Materno Infantil. Hospital Regional Universitario de Mälaga, Pediatria., Málaga, Spain; ${ }^{4}$ Instituto de Investigación Biomédica de Málaga (IBIMA). Hospital Regional Universitario de Malaga. Universidad de Malaga, Reumatología, Màlaga, Spain

Background: In recent years, several studies show contradictory results regarding body composition in juvenile idiopathic arthritis. Adiposity in Rheumatoid Arthritis and Psoriasic Arthritis has been associated to inflammatory activity, but it is not clear what happens in JIA.

Objectives: To describe the body composition and anthropometric parameters of patients with JIA compared with healthy controls and analyze associated risk factors in JIA patients.

Methods: Observational cross-sectional study in spanish children aged 4-15 years with JIA compared with healthy controls matched for age and sex. We recorded epidemiological variablesanthropometric parameters, clinical data and validated physical activity questionnaires. Body composition was measured using dual-energy $\mathrm{x}$-ray absorptiometry (DXA), and included total mass $(\mathrm{kg})$, fat mass (g), lean mass $(\mathrm{g})$, and lean mass and android and gynoid fat mass. The fat mass index $(\mathrm{FMI})$ was defined as fat mass $(\mathrm{kg}) /$ height squared $\left(\mathrm{m}^{2}\right)$ and fat-free mass index (FFMI) as fat-free mass $(\mathrm{kg}) /$ height squared $\left(\mathrm{m}^{2}\right)$. Descriptive, bivariete and two multivariate models were constructed to identify factors associated with obesity and fat mass in JIA patients.

Results: We analyze 160 subjects: 80 patients with JIA and 80 healthy controls. The baseline characteristics of both groups are shown in Table 1. No differences were found between both groups in BMI $(p=0.936)$, fat mass $(p=0.449)$, lean mass $(p=0.793)$ and in fat and lean mass of legs, arms and trunk, or in physical activity questionnaire $(p=0.582)$. The factors associated with obesity in patients with JIA were: time with biological drug (OR $[95 \% \mathrm{Cl}]=1.12$ [1.01-1.04]; $p=0.042)$ and sedentary lifestyle $(\mathrm{OR}[95 \% \mathrm{Cl}]=3.50[1.18-7.35] ; p=0.023)$; while the factors associated with the fat mass index were: age $(\mathrm{B}[95 \% \mathrm{Cl}]=0.30[0.16-1.41]$ $\mathrm{p}=0.014)$, inflammatory activity $(\mathrm{JDAS})(\mathrm{B}[95 \% \mathrm{Cl}]=0.44[0.16-1.08] ; \mathrm{p}=0.009)$ and physical activity $(\mathrm{B}[95 \% \mathrm{Cl}]=-0.22[-0.10,-0.28] ; p=0.031)$.

Table 1. Baseline characteristics of patients with JIA and controls

\begin{tabular}{|c|c|c|c|}
\hline Variable & $\mathrm{JIA}(\mathrm{n}=80)$ & Controls $(n=80)$ & P-value \\
\hline Sex, girls n (\%) & $56(70.0)$ & $57(71.3)$ & 0.862 \\
\hline Age, mean (SD) & $10.7(3.2)$ & $10.2(3.2)$ & 0.893 \\
\hline \multirow{2}{*}{\multicolumn{4}{|c|}{ JIA subtype }} \\
\hline & & & \\
\hline Systemic, n (\%) & $9(11.3)$ & & \\
\hline Oligoarticular persistent, $n$ (\%) & $38(47.5)$ & & \\
\hline Oligoarticular extended, $\mathrm{n}(\%)$ & $13(16.3)$ & & \\
\hline Rheumatoid Factor-positive polyarticular, n (\%) & $1(1.3)$ & & \\
\hline Rheumatoid Factor-negative polyarticular, n (\%) & 19(23.8) & & \\
\hline CRP (mg/l), mean (SD) & $4,8(9,5)$ & & \\
\hline ESR $(\mathrm{mm} / \mathrm{h})$, mean (SD) & $8.8(7,3)$ & & \\
\hline JADAS27, mean (SD) & $2(4.0)$ & & \\
\hline CHAQ, mean (SD) & $0.17(0.4)$ & & \\
\hline \multicolumn{4}{|l|}{ Treatment } \\
\hline DMARDs (synthetic), n (\%) & $42(52.5)$ & & \\
\hline DMARDs (biological), n (\%) & $24(30.0)$ & & \\
\hline Anti IL-1, n (\%) & $4(16.7)$ & & \\
\hline Anti IL-6, n (\%) & $2(8.3)$ & & \\
\hline Anti TNF- $\alpha, \mathbf{n}(\%)$ & $18(75.0)$ & & \\
\hline \multicolumn{4}{|l|}{ Treatment duration } \\
\hline DMARDs synthetic, (months), mean ( \pm SD) & $51(37.5)$ & & \\
\hline DMARDs biological, (months), mean ( \pm SD) & $19.7(28.4)$ & & \\
\hline DMARDs total (months), mean $( \pm S D)$ & $55.8(38.0)$ & & \\
\hline Cumulative corticoisteroids dose, median (range) & $1.3(0.12-870$ & & \\
\hline
\end{tabular}

Abreviaturas; JIA: juvenile idhipathic arthritis; SD: standart deviation; CRP: C-reactive protein; VSG:erytrocyte sedimentation rate; JADAS27: Juvenile Arthritis Disease Activity Score; CHAQ: Childhood Health Assessment; DMARD: disease-modifyng anti-rheumatic drug. 